\title{
Aging Experience in Asia: A Sociological Appraisal
}

\author{
Mohammad Taghi Sheykhi* \\ Professor Emeritus of Sociology, Alzahra University,Tehran, Iran \\ *Corresponding author: Mohammad Taghi Sheykhi, Professor Emeritus of Sociology, Alzahra University, Tehran, Iran
}

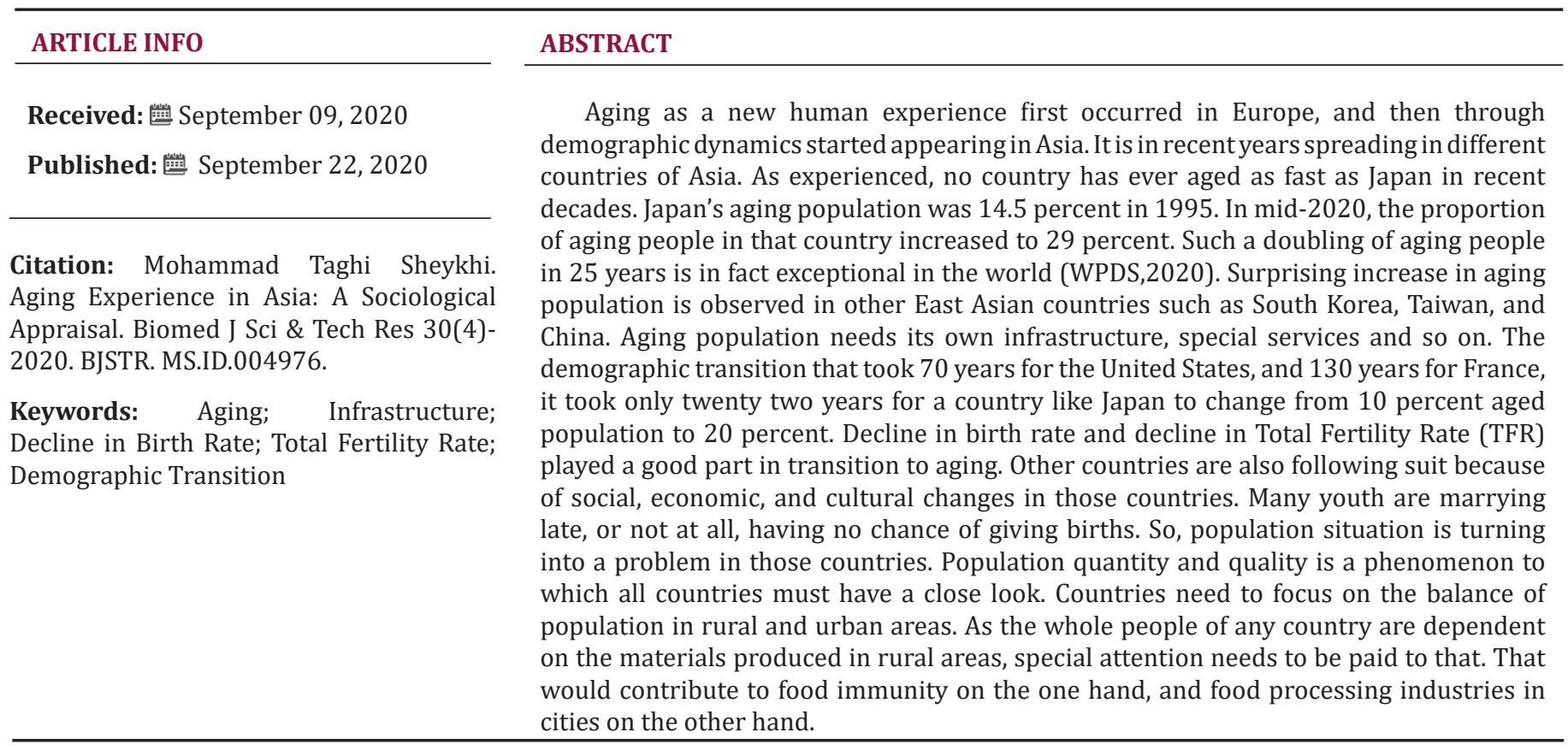

\section{Introduction}

Sociology as a comprehensive social discipline apprising and investigating various phenomena, will now analyze the state of childbirth worldwide. For almost all women childbirth is a natural and happy experience through which new life is brought into the world. But, for increasing number of women who live in developing countries such as Niger, India, or Uganda, Childbirth are a risky endeavor. Though humanity has so far continued through childbirth, and a result of which has been continuity of generations among nations regardless of race, creed or religion, childbirth is facing complications because of science, technology, migration, and organization around the world. Some countries that more scientifically developed, face less problems, so far as childbearing is concerned. One of the risks of pregnancy and childbirth is associated with pregnancy- related deaths of women/ mothers. Repeated and back- to- back pregnancies can deplete the mother's essential nutrients, giving the mother the risk of anemia and other complications including death. The babies of such mothers are at the risk of low birth weight and preterm birth. In the countries where mothers give birth of 7-8 babies, mother remains at very high risk. However, there is a clear connection between high fertility rate and maternal mortality rate. UNICEF indicates that women in countries like Niger, Afghanistan, Sierra Leon, Chad, Angola and many more, are at high risks of pregnancy-related diseases and other complications. According to UNICEF lives of the newborns as well as the mothers could be saved simply through right medications, improving health measures, educational development for the girls and the like. All such measures strongly save maternal deaths. In case women and girls are provided a low status in the society, their health needs are more often neglected.

\section{Method of Research}

Methodology used in the present article is of qualitative type. In that, various paradigms have been used to find out facts regarding divorce. Qualitative research usually studies people or 
areas in their natural settings. In finding facts for the research, the researcher engaged in careful data collection and thoughtful analysis of what was relevant. In the documentary research applied in the present article, printed and written materials were widely regarded. The research was performed as a qualitative library type in which the researcher had to refer to relevant and related sources. In the current research various documents were thoroughly investigated, and the needful inferences were made. The data fed by the investigator in the present article is hopefully reliable. Though literature on childbirth is very limited, yet the author tried to investigate many different resources in order to elicit the necessary information to build up the text.

\section{Birth Rate}

Childbearing comes into being through fertility achievement, and via male-female connection. According to United Nations, "Natural Fertility is the fertility which exists in the absence of deliberate birth control" [1]. According to the same source, controlled fertility is the fertility that involves a deliberate use of birth control [2]. On the other hand, the term birth control is used in a broad of sense to include international abortions, sterilization, and complete abstinence from coitus. Contraceptive method is sometimes taken as identical with birth control method. though it is a part of it. However, most persons use contraception and birth control in the same sense. Contraception, as is clear by the term is opposite of conception. Fertility refers to the actual reproductive performance_ applied to an individual or a group [3]. Fertility can be measured through birthrate. So, a woman who has given birth to a live child is considered fertile. On the other hand, those who have not produced a single child are considered sterile. The total number of children born by one couple are known as "Family Size". The physiological limits of childbearing capacity and period are known as "Theoretical Maximum Fertility". Similarly, abortions and still birth are classified as reproductive wastage. All those concepts are understood as the trends and causes of childbirth and fertility (Table 1).

Table 1: Average age of first birth in selected developed nations by age, 2015.

\begin{tabular}{|c|c|}
\hline US & 26.4 \\
\hline Latvia & 26.5 \\
\hline Poland & 27.0 \\
\hline Slovakia & 27.1 \\
\hline Estonia & 27.2 \\
\hline Iceland & 27.5 \\
\hline Hungary & 27.9 \\
\hline Czech Republic & 28.2 \\
\hline Canada & 28.5 \\
\hline France & 28.5 \\
\hline Belgium & 28.7 \\
\hline
\end{tabular}

\begin{tabular}{|c|c|}
\hline Slovenia & 28.7 \\
\hline UK & 28.7 \\
\hline Finland & 28.8 \\
\hline Norway & 28.9 \\
\hline Austria & 29.2 \\
\hline Denmark & 29.2 \\
\hline Sweden & 29.2 \\
\hline Germany & 29.5 \\
\hline Portugal & 29.5 \\
\hline Ireland & 29.5 \\
\hline Netherlands & 29.7 \\
\hline Greece & 30.2 \\
\hline Luxembourg & 30.2 \\
\hline Switzerland & 30.6 \\
\hline Japan & 30.7 \\
\hline Spain & 30.7 \\
\hline Italy & 30.8 \\
\hline South Korea & 31.4 \\
\hline
\end{tabular}

Note: All statistics are based on OECD countries available.

\section{Maternal Mortality vs Birth Rate}

Maternal mortality is unacceptably high more because of increasing childbirths among the women with the special reference to the developing countries. Majority of such deaths or about $90 \%$ occurring in low-infrastructural countries, and most could have been prevented [4]. Similarly, South Asian countries, and Sub-Saharan countries in Africa, approximately involved 254000 or $86 \%$ of the world maternal deaths in 2017. Risk of maternal mortality is highest for adolescent girls under the age of 15 years old and the complications in pregnancy and childbirth are higher among girls 10-19 as compared with age groups 20-24 [5].Such catastrophes leave behind increasing issues for the remaining children in different stages of their lives. Such mother-less children cannot easily access education, proper socialization, and alike. Eventually, they get into child-labor; a situation which will impact next generation as well.In high income countries one in every 5400 die as a result of maternal death, while one in 45 happens in low income countries. Women die as a result of complications during and following pregnancy and childbirth. However, most of such complications are treatable if infrastructure is available. In case clinical management is maintained, a large number maternal deaths among the women in developing countries could be prevented [6]. Poverty distance to facilities, lack of information, inadequate and poor quality services, and finally cultural beliefs and practices are known as the main causes of maternal deaths [7].In countries like Poland, Iceland, Norway and ... there are only three maternal deaths versus every 100,000 births; Leaving behind golden opportunities for children so far as socialization and education are concerned. 


\section{Health Policy vs Childbirth}

During the past three decades many organizations have been engaged with progressive and planning toward childbirth in increasing number of countries. In that, private providers have been active in low and middle- income countries in an effort to improve the reproductive behavior in the process of fertility $[8,9]$. In some countries public and private health facilities both act simultaneously based on the choice of the clients, and quality and cost [10]. But currently the available data do not show the increasing and in-depth interfere of the private sector so far as maternal health across countries is concerned. In some cases, mothers who refer to a facility for delivery care, they may choose the private facilities. Though in many countries the public facilitates is the main and first choice, yet for some reasons, some women may choose the private facilities. Literature on facility choice has found a wide range of determinants. Evidence through Asia has shown that socio- demographic groups most often of higher education contribute to private facilities choice by the women [11-15]. Other relevant factors like ethnicity and caste status are highly associated with the use of private facilities in India. Besides that, quality of income in the family plays a determining part in the choice (Table 2).

Table 2: Average number of lifetime births in selected developed nations by age, 2015 .

\begin{tabular}{|c|c|}
\hline Iceland & 2.3 \\
\hline US & 2.2 \\
\hline Norway & 2.1 \\
\hline France & 2.0 \\
\hline Sweden & 2.0 \\
\hline Slovakia & 1.9 \\
\hline UK & 1.9 \\
\hline Finland & 1.9 \\
\hline Hungary & 1.9 \\
\hline Estonia & 1.9 \\
\hline Czech Republic & 1.8 \\
\hline Canada & 1.8 \\
\hline Netherlands & 1.8 \\
\hline Poland & 1.8 \\
\hline Slovenia & 1.7 \\
\hline Portugal & 1.7 \\
\hline Switzerland & 1.6 \\
\hline Austria & 1.6 \\
\hline Germany & 1.5 \\
\hline Italy & 1.5 \\
\hline Spain & 1.5 \\
\hline Japan & 1.5 \\
\hline
\end{tabular}

Note: All statistics are based on OECD countries available.

\section{Birth Rate in East Asia}

Birth rates have widely fallen below 2.1 with the special reference to South Korea where it has impacts on economic growth, cultural stability, and other characteristics [16]. Declining fertility rate and contraction of labor force on the one hand, may have negative effects on economic growth and on the other hand, it has increased the wages of the current labor force_ Facilitating pensions, education, health care services etc. $[17,18]$. South Korea has been experiencing a dramatic decline in birthrate since 1916 when six children were born to per woman, and now it is known as one of the countries with the lowest birthrate in the world [19]. While the number of kids and the youth declines, and the proportion of aging people increases, such a decline, in work force will ultimately impact the country's economic vitality, with regard to increased costs of health's and social care services [20].

Industrialization is known to be a driving force for the decline in fertility in developing countries where technological and financial help for birth control is provided by international organizations. In addition, the decreasing birthrate is associated with norms, values and attitudes regarding marriage, lifestyle, parenthood, gender role, attitudes, gender quality values etc. [20,21]. Similarly, higher rate unemployment of young adults, nuclear family formation, gender equality issues and the like all helped change in family patterns in South Korea. The phenomenon has been continuing to the recent time. Population planning in South Korea has widely helped the country to grow up its industries, economy, international trade and overall, its GDP per capital as compared with other Asian and developing countries. Currently, right after Japan, South Korea is counted as the most developed country in Asia.

\section{East Asian Marriage and Family}

East Asia is known as symbol of population policy and planning during the past half-century. Family behaviors and patterns widely changed in china, Japan, South Korea, and Taiwan. These countries pay much attention to the family lineage and ancestor worship particularly Pronounced in Chinese culture [22]. A great value in Chinese family is that children or grandchildren must respect for the parent or grandparents [23]. It happens so with South Korean families and perhaps to a lesser degree with Japanese Families [24]. China declared its one- Child Family in 1979; a plan that highly changed the family values and norms, brought more employment for the women, gave them more economic independence, gave them better health and so on. Single- child family continued in china until 2015, when the family was permitted to have a second child then. Pressure of labor and employment caused the marriage age and childbearing to increase; the phenomenon that caused Total Fertility Rate (TFR) to decline, and even many families remain childless in their lives. The whole scenario has contributed to the increase of the elderly people in those countries. Aging of population is also penetrating into the other developing countries 
too. The social and demographic changes entered the above four countries, will continue within the emerging generations in the years to come. Such milestones will remain and even switch to other generations contributing to further social changes in future. The demographic scenario will lead to shortage of babies which must be compensated by electronic man force (Table 3 ).

Table 3: \% of women who never gave birth in selected developed nations, 2015.

\begin{tabular}{|c|c|}
\hline Czech Republic & $9 \%$ \\
\hline Hungary & $11 \%$ \\
\hline Denmark & $12 \%$ \\
\hline Portugal & $12 \%$ \\
\hline Slovakia & $12 \%$ \\
\hline Norway & $13 \%$ \\
\hline Slovenia & $14 \%$ \\
\hline US & $14 \%$ \\
\hline Sweden & $14 \%$ \\
\hline France & $14 \%$ \\
\hline Belgium & $16 \%$ \\
\hline Netherlands & $18 \%$ \\
\hline UK & $18 \%$ \\
\hline Ireland & $19 \%$ \\
\hline Austria & $19 \%$ \\
\hline Switzerland & $19 \%$ \\
\hline Finland & $20 \%$ \\
\hline Spain & $21 \%$ \\
\hline Italy & $21 \%$ \\
\hline Germany & $23 \%$ \\
\hline
\end{tabular}

Note: All statistics are based on OECD countries available.

\section{State of Childbirth in Africa}

Childbirth in Africa is very poor and heartbreaking _ most often it causes the death of mother in the family. Pregnancy and childbirth complications are very common in developing countries, but much wider in African countries. Yet, women are known as source of wealth and health in their communities, and without them family will not continue. In Africa, as found out, an amazing one woman in every 22 women dies in pregnancy- related complications, there as in UK one in every 8000 deliveries leads to a maternal death. Traditions and norms contribute to repeated and continued births within the African women. Shortage of access to quality facilities transportation and trained midwifes escalate the problem. Many women in remote areas have to deliver their babies just at home where they are likely to catch diseases or die. But if there is a mother or grandmother beside her the chance of having a healthy baby and the unlikeliness of maternal death increases. On the other hand, lack of transport and having to walk to the delivery center increases the chance of maternal death in African society.
Women undervalued and highly vulnerable, they try to have more sons, a motion that increases their Total Fertility Rate (TFR). However, newborn health and survival are much linked to the care the mother receives before and during pregnancy, childbirth, and postnatal period. Throughout the continuum of care, the period of highest risk of disability and death, there are threats for both mothers as well the newborns. Labor, in the first few hours after delivery is there. Complications at this time are very likely for both mothers and babies with grave consequences. So, African countries need more investments and infrastructures to improve the situation so far as the maternal mortality and vulnerability are concerned (Table 4).

Table 4: State of maternal mortality in selected industrial countries, 2015.

\begin{tabular}{|c|c|}
\hline Sweden & 4 \\
\hline Norway & 5 \\
\hline Switzerland & 5 \\
\hline Austria & 6 \\
\hline Germany & 6 \\
\hline Canada & 7 \\
\hline Netherlands & 7 \\
\hline France & 8 \\
\hline UK & 9 \\
\hline New Zealand & 11 \\
\hline US & 14 \\
\hline
\end{tabular}

Note: All statistics are based on OECD countries available.

\section{Causes of Low Fertility in Asia}

Social modernization has caused increasing social change in many parts of Asia, among which low fertility is an effect. Social modernization as increased schooling, extended average age of marriage, decreased marriage events and those occurred in later ages, get the chance of fewer child bearings. Besides, as marriages happen late, many families cannot reach their son preference that they really wish for. So many of such countries will later face the imbalance of sex ratio. Low fertility though not an issue at the time being, it will be problematic later. So, the high most causes of decreasing are the rise in Women education levels and employment rates. Currently, the four Asia's most prosperous economies _ Japan, Singapore, South Korea, and Taiwan, now have the lowest birthrates in the world despite the reported statistics, Survey results declare that all the young women in this societies wish to marry and have children. Butactually, speaking lack of childbearing in many parts of the world. Results in aging of population and shortage of young man-power. However, despite maternity leave and children leave from work, assistance with childcare through daycare centers after school programs provision of housing facilities, medical insurance, expenses related to pregnancy and childbirth, women do not accept regular marriage and child baring.As sociologically observed, 
fertility in East Asian countries will remain low at least foreseeable future. Economic competition within the societies concern, will retain population growth at very low rate for the coming years.

\section{Conclusion}

Sociology as a multi- Dimensional discipline evaluates childbirth from different angles. This natural event is under social, economic, and political decisions of governments. It is also under the quality of poverty and affluence of governments in different countries of the world, Countries with fast growing economies the initiative of lowering the birthrates by any means. Similarly, as lifestyles of the youth is ever changing by education, employment, and other patterns, they marry late in their lives and get fewer children or none at all. Also, as death rate has maximally declined, increasing number of young families do not have the motive to plan for large families. Change of standards like high quality of life, better education, better nutrition, and many more, have motivated young couples towards smaller families. In countries where male, female connections have been liberalized, family formation happens late, and the child is not anymore, a value within many families. Birth control being highly used, it has lower total fertility rate among many women. While the average TFR is 4.1 in the least developed countries, it is 1.6 in developed countries. This means that in developed countries 1.6 people replace two who die, and in this way Population in these crimes gradually shrinks, While in African countries the situation is reversed, and in that, population size annually boosts. The Phenomenon that leads poverty and lower quality of life. Increasing childbirth highly affects maternal and infant mortality rate. Many developing countries need to introduce effective policies to plan the population. In this way, they help themselves as well as the world as a whole.

\section{References}

1. Ajzen I (2013) Fertility Intentions: An Approach Based on the Theory of Planned Behavior 29: 203-232.

2. Arpino B (2015) How Do Changes in Gender Role Attitudes Towards Female Employment Influence Fertility? A Macro-Level Analysis 31(3): 370-382.

3. Berman P, Rose L (1996) The Role of Private Provider in Maternal and Child Health and Family Planning Services in Developing Countries. Health Policy and Planning. 11(2): 142-155.

\section{ISSN: 2574-1241}

DOI: $10.26717 /$ BJSTR.2020.30.004976

Mohammad Taghi Sheykhi. Biomed J Sci \& Tech Res

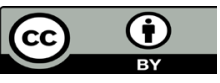

This work is licensed under Creative Commons Attribution 4.0 License

Submission Link: https://biomedres.us/submit-manuscript.php
4. East- West Center. (2010) Honolulu, Hawaii.

5. Ferrinho P (2001) Is there a case for Privatizing Reproduction Health? Patchy Evidence and much Wishful Thinking. Studies in Health Services Organization and Policy, Google Scholar.

6. Ganching T (2014) Pregnancy and Childbirth Outcomes among Adolescent Mothers, A World Health Organization Multicounty Study. BJOG 121(Suppl 1): 40-48.

7. Hanson K, Berman P (1998) Private Health Care Provision in Developing Countries: A Preliminary of Levels and Composition, Health Policy and Planning. Health Policy Plan 13(3): 195-211.

8. Hashimoto A, Ikels C (2005) Filial Piety in Changing Asian Societies, Handbook of Age and Aging. In Hashimoto A, Ikels C (Eds.), Cambridge University Press, Cambridge, England.

9. Harper S (2014) Economic and Social Implications of Aging Societies. Science 346(6209): 587-591.

10. Ibid pp. 38.

\section{Ibid pp. 78.}

12. Lunenfeld B (2014) The Clinical Consequences of an Aging World and Preventive Strategies. Best Pract Res Clin Obstet Gynaecol 27(5): 643659.

13. Repetto R (2013) Economic Equality and Fertility in Developing Countries. New York: RFF Press.

14. Retrieved, 2020.

15. Say L (2014) Global Causes of Maternal Death: A WHO Systematic Analysis. Lancet Glob Health 2(6): e323-333.

16.(2015) Strategies towards Ending Preventable Maternal Mortality (EPMM), World Health Organization.

17. Thompson LG (1989) Chinese Religion: An Introduction, 4. Belmont, CA: Wadsworth.

18. Thosto A, Lin HS (1994) Social Change and Family in Taiwan. Chicago: University of Chicago Press. 55(2): 451-453.

19. Thind A (2008) Where to Deliver? Analysis of Choice of Delivery Location from a National Survey in India, BMC Public Health.

20. Trends in Maternal Mortality (2019) 2000-2017: Estimated by WHO, UNICEF, UNFPA, World Bank and the United Nations Population Division, Geneva, USA.

21. (1973) United Nations, The Determinants and Consequences of Population Trends, Population Studies 1(50).

22. (2020) World Population Data Sheet, Washington DC. USA.

23. Xing Y (2016) Japanese Economy: Facing the Constraints of an Aging and Declining Population, East Asian Policy 8(1): 79-94.

24.Zwi AB (2001) Private Health Care in Developing Countries. British Medical Journal. 323(7311): 463-464.

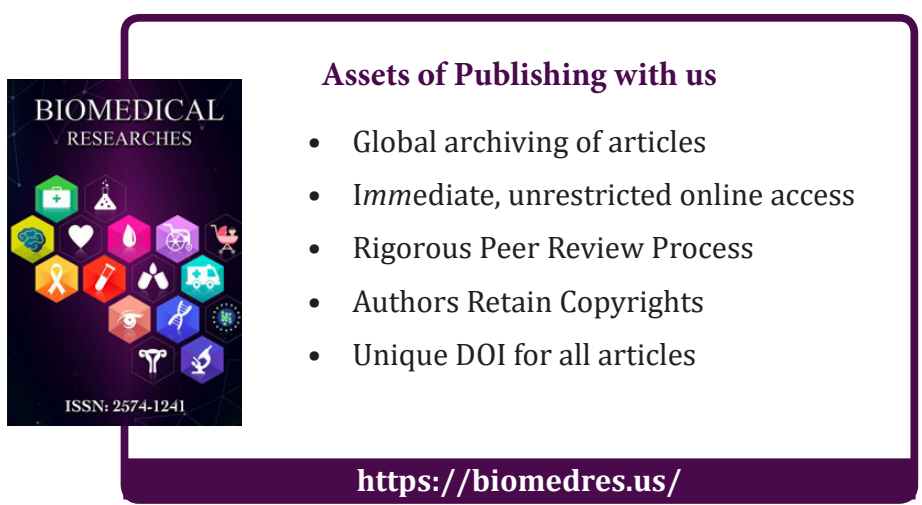

